\title{
The Effects of Retinoic Acid and MAPK Inhibitors on Phosphorylation of Smad2/3 Induced by Transforming Growth Factor $\beta 1$
}

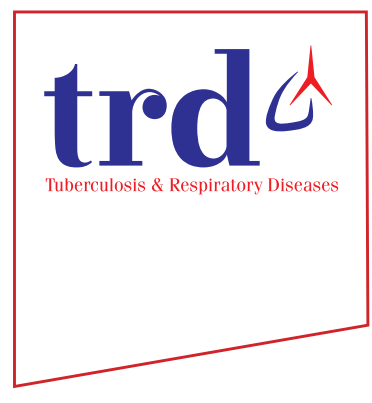

\author{
Sang Hoon Lee, M.D. ${ }^{1,2}$, Ju Hye Shin, M.S. ${ }^{1}$, Mi Hwa Shin, B.S. ${ }^{1}$, Young Sam Kim, M.D., Ph.D. ${ }^{1}$, \\ Kyung Soo Chung, M.D. ${ }^{1}$, Joo Han Song, M.D. ${ }^{1}$, Song Yee Kim, M.D., Ph.D. ${ }^{1}$, Eun Young Kim, M.D., \\ Ph.D. ${ }^{1}$, Ji Ye Jung, M.D., Ph.D. ${ }^{1}$, Young Ae Kang, M.D., Ph.D. ${ }^{1}$, Joon Chang, M.D., Ph.D. ${ }^{1}$ and Moo \\ Suk Park, M.D., Ph.D. ${ }^{1}$ \\ ${ }^{1}$ Division of Pulmonary and Critical Care Medicine, Department of Internal Medicine, Institute of Chest Diseases, Severance \\ Hospital, Younsei University Health System, Yonsei University College of Medicine, Seoul, ${ }^{2}$ Division of Pulmonary and Critical \\ Care Medicine, Department of Internal Medicine, Seoul National University Bundang Hospital, Seoul National University \\ College of Medicine, Seongnam, Korea
}

Background: Transforming growth factor $\beta$ (TGF- $\beta$ ), retinoic acid (RA), p38 mitogen-activated protein kinase (MAPK), and MEK signaling play critical roles in cell differentiation, proliferation, and apoptosis. We investigated the effect of RA and the role of these signaling molecules on the phosphorylation of Smad2/3 (p-Smad2/3) induced by TGF- $\beta 1$.

Methods: A549 epithelial cells and CCD-11Lu fibroblasts were incubated and stimulated with or without all-trans RA (ATRA) and TGF- $\beta 1$ and with MAPK or MEK inhibitors. The levels of p-Smad2/3 were analyzed by western blotting. For animal models, we studied three experimental mouse groups: control, bleomycin, and bleomycin+ATRA group. Changes in histopathology, lung injury score, and levels of TGF- $\beta 1$ and Smad 3 were evaluated at 1 and 3 weeks.

Results: When A549 cells were pre-stimulated with TGF- $\beta 1$ prior to RA treatment, RA completely inhibited the p-Smad2/3. However, when A549 cells were pre-treated with RA prior to TGF- $\beta 1$ stimulation, RA did not completely suppress the p-Smad2/3. When A549 cells were pre-treated with MAPK inhibitor, TGF- $\beta 1$ failed to phosphorylate Smad2/3. In fibroblasts, p38 MAPK inhibitor suppressed TGF- $\beta 1$-induced p-Smad2. In a bleomycin-induced lung injury mouse model, RA decreased the expression of TGF- $\beta 1$ and Smad 3 at 1 and 3 weeks.

Conclusion: RA had inhibitory effects on the phosphorylation of Smad induced by TGF- $\beta 1$ in vitro, and RA also decreased the expression of TGF- $\beta 1$ at 1 and 3 weeks in vivo. Furthermore, pre-treatment with a MAPK inhibitor showed a preventative effect on TGF- $\beta 1 /$ Smad phosphorylation in epithelial cells. As a result, a combination of RA and MAPK inhibitors may suppress the TGF- $\beta 1$-induced lung injury and fibrosis.

Keywords: Transforming Growth Factor Beta; Retinoic Acid; Mitogen-Activated Protein Kinases; MEKs; Smad Proteins

\footnotetext{
Address for correspondence: Moo Suk Park, M.D., Ph.D.

Division of Pulmonary and Critical Care Medicine, Department of Internal Medicine, Institute of Chest Diseases, Severance Hospital, Yonsei University Health System, Yonsei University College of Medicine, 50-1 Yonsei-ro, Seodaemun-gu, Seoul 03722, Korea

Phone: 82-2-2228-1955, Fax: 82-2-393-6884, E-mail: pms70@yuhs.ac

Received: Sep. 28, 2017, Revised: Jan. 15, 2018, Accepted: Mar. 23, 2018, Published online: Jun. 19, 2018
}

() It is identical to the Creative Commons Attribution Non-Commercial License (http://creativecommons.org/licenses/by-nc/4.0/). 


\section{Introduction}

Abnormal wound healing in pulmonary fibrosis is characterized by fibroblast and myofibroblast migration and proliferation, decreased myofibroblast apoptosis, and increased activity of and responses to fibrogenic cytokines, especially transforming growth factor $\beta 1$ (TGF- $\beta 1)^{1-3}$.

TGF- $\beta$ induces phosphorylation of Smad2/3, which is released and further propagates the signal of TGF- $\beta$. Changes in the level of Smad have been reported in human fibroblasts and epithelial cells following treatment with glucocorticoids, interferon- $\gamma$, and pirfenidone ${ }^{4-6}$. TGF- $\beta 1$ utilizes not only the Smad pathway, but also non-Smad pathways. These nonSmad pathways include the following signaling pathways and molecules: the phosphatidylinositol-3-kinase (PI3K)/ Akt pathways, mitogen-activated protein kinase (MAPK), and Rho-like GTPase ${ }^{7}$. Pendaries et al. ${ }^{8}$ reported that retinoic acid receptors (RARs) interfere with the TGF- $\beta$ signaling pathway.

Retinoic acids (RAs), which are active vitamin A derivatives, play a critical role in cell differentiation, proliferation, and apoptosis $^{8-10}$. It has been established that RA exerts its action through the activation of RARs and retinoid $\mathrm{X}$ receptors that regulate various transcriptional factors ${ }^{11}$. Understanding the roles of RA can provide new insights into the products of oncogenes/suppressor genes and the chronic fibrosis of human organs as it is associated with the TGF- $\beta_{1}$ signaling pathway.

Additionally, it is well-known that TGF- $\beta 1$ activates the extracellular-signal-regulated kinase and the MAPK pathway through mitogen-activated protein/extracellular signal-regulated kinase (MEK) in the non-Smad pathway?

The purpose of this investigation was to determine whether RAs could inhibit the TGF- $\beta 1$ induced phosphorylation of Smad2/3, and to determine the difference in TGF- $\beta 1$ expression between epithelial cells and fibroblasts upon pretreatment with MAPK inhibitors. Additionally, we aimed to compare the degree of expression between phospho-Smad2 (p-Smad2) and 3 (p-Smad3) in each cell type. Furthermore, we intended to confirm the effect of TGF- $\beta 1$ and RA in a bleomycin-induced lung injury and fibrosis mouse model.

\section{Materials and Methods}

\section{Human epithelial cell line and fibroblast cell line}

The A549 epithelial and CCD-11Lu fibroblast cell lines that were used for the experiments in this study were purchased from the American Type Culture Collection (ATCC, Rockville, MD, USA).

The study design in this report was approved by the Institutional Animal Care Committee at the Medical College of Yonsei University (2014-0368). This experiment was performed in compliance with recommendations in the Guide for the Care and Use of Laboratory Animals by the National Institutes of Health.

\section{Chemicals and antibodies}

TGF- $\beta 1$ was purchased from Calbiochem (San Diego, CA, USA). Three types of RA, including all-trans retinoic acid (ATRA), 9-cis RA, and 13-cis RA were purchased from SigmaAldrich (St. Louis, MO, USA). The primary antibodies to Smad proteins for use in western blotting were obtained from Cell Signaling Technology (Danvers, MA, USA) and Zymed (San Francisco, CA, USA). $\beta$-Actin was used as a negative control, and was obtained from Delta Biolabs (Gilroy, CA, USA). The MEK 1/2 inhibitor, U0126, was purchased from Cell Signaling Technology (Beverly, MA, USA) and the p38 MAPK inhibitor (SB203580) was purchased from Santa Cruz Biotechnology (Santa Cruz, CA, USA).

\section{Cell culture and chemical stimulation}

A549 cells were cultured in RPMI 1640 medium (Gibco BRL, Grand Island, NY, USA) supplemented with $10 \%$ fetal bovine serum (FBS; Gibco BRL). CCD-11Lu cells were cultured in EMEM (Beckton Dickinson \& Company, Lincoln Park, NJ, USA). Cells were incubated at $37^{\circ} \mathrm{C}$ with $5 \% \mathrm{CO}_{2}$ for 24 -hour durations, and subcultured two-to-three times, weekly, to maintain $\log$ phase growth.

To examine the effects of RA on the phosphorylation of Smad induced by TGF- $\beta 1$, A549 cells were stimulated as follows: (1) TGF- $\beta 1$, (2) RA, (3) 1 hour pre-stimulated with TGF- $\beta 1$ prior to RA treatment, and (4) 1 hour pre-treated with RA prior to TGF- $\beta 1$ stimulation. As a negative control, cells were incubated with only culture medium.

In total, $10^{-6} \mathrm{~mol} / \mathrm{L}$ of each individual RA and $/$ or $5 \mathrm{ng} / \mathrm{mL}$ of TGF- $\beta 1$ were administered to the cells. RA and TGF- $\beta 1$ were administered to A549 cells without delay. After stimulation, A549 cells were incubated for 24 hours, and then subjected to western blotting, as described below.

In a separate experiment, to investigate the effects of TGF- $\beta 1$ on A549 cells and CCD-11Lu cells, each cell line was pre-treated with a 338 MAPK inhibitor, a MEK $1 / 2$ inhibitor, or neither (control). These pre-treated cells were stimulated as described above; (1) TGF- $\beta 1$, (2) RA, (3) pre-stimulated with TGF- $\beta 1$ prior to RA treatment, and (4) pre-treated with RA prior to TGF- $\beta 1$ stimulation.

\section{Western blotting analysis (in vitro)}

$2 \times 10^{6}$ cells were dissolved in $100-\mathrm{mm}$ culture plates and pre-incubated with RPMI 1640 medium. After 24 hours in the presence or absence of chemical stimulation, as described above, cells were washed twice with cold phosphate buffered saline (PBS), scraped and solubilized in a RIPA-B buffer con- 
taining $0.5 \%$ nonidet P-40, $20 \mathrm{mM}$ Tris- $\mathrm{HCl}$ (pH 8.0), $50 \mathrm{mM}$ $\mathrm{NaCl}, 50 \mathrm{mM} \mathrm{NaF}, 100 \mu \mathrm{M} \mathrm{Na}_{3} \mathrm{VO}_{4}, 1 \mathrm{mM}$ DTT, $50 \mu \mathrm{g} / \mathrm{mL}$ phenylmethanesulfonylfluoride, $20 \mu \mathrm{g} / \mathrm{mL}$ aprotinin, and 20 $\mu \mathrm{g} / \mathrm{mL}$ leupeptin. After 30 minutes at $4^{\circ} \mathrm{C}$, cell lysates were cleared of debris by centrifugation at $12,000 \mathrm{rpm}$ at $4^{\circ} \mathrm{C}$ for 20 minutes. The protein lysates $(20 \mu \mathrm{g})$ were applied to $10 \%$ sodium dodecyl sulfate polyacrylamide gel electrophoresis gel (SDS-PAGE) gels and transferred to nitrocellulose membranes (Amersham Biosciences, Piscataway, NJ, USA). The membranes were blocked at room temperature with $5 \%$ skim milk in TBST ( $1 \times$ TBS, $0.1 \%$ Tween 20). After washing twice in TBST, the membranes were incubated with primary Smad antibodies for 2 hours at room temperature. The membranes were then washed 3 times for 10 minutes, each, in TBST, and incubated with the relevant horseradish peroxidase-conjugated secondary antibodies (diluted 1:1,000 in 3\% bovine serum albumin in TBST) for 1 hour. After washing three times in TBST, the reactive proteins were visualized using an enhanced chemiluminescence detection system (Amersham Biosciences).

\section{Bleomycin-induced lung injury and fibrosis model}

Male C57BL/6J mice, 7 weeks old and weighing 18-22 g, were purchased from Orient Bio (Seongnam, Korea). Mice were provided with rodent food and water in a controlled environment. Twelve mice were divided into the following three groups (n=4/group): (A) a control group with PBS inhalation, (B) a bleomycin plus PBS group, and (C) a bleomycin plus ATRA (25 mg/kg) group. Bleomycin (3 mg/mL; Dong-A Pharmaceutical, Co., Ltd., Seoul, Korea) was dissolved in PBS $(3 \mathrm{~mL})$. The mice were first lightly anesthetized by inhalation of isoflurane (Abbott Laboratories, North Chicago, IL, USA) in a supine position, and then PBS and bleomycin $(50 \mu \mathrm{L})$ were administered intranasally. In the bleomycin plus ATRA group, $0.5 \mathrm{mg}$ of ATRA (Sigma) powder dissolved in $0.1 \mathrm{~mL}$ dimethyl sulfoxide (DMSO) was injected. In the bleomycin plus ATRA group, bleomycin was only once inhaled and ATRA was injected three times per week, through intrapenitoneum. To collect lung specimens, the experimental mice were sacrificed on day 7 or day 21 using a lethal overdose of xylazine.

\section{Histology}

The pulmonary artery was flushed with sterile saline at low pressure, and the right lung was excised and stored at $-80^{\circ} \mathrm{C}$. Before the left lung was excised, it was inflated via tracheotomy using $4 \%$ low-melting point agarose in PBS at 25 $\mathrm{cm}_{2} \mathrm{O}$ pressure until pleural margins became sharp. After the left lungs were excised, the mouse lung tissues were fixed overnight in 10\% formaldehyde in PBS, and embedded in paraffin. Serial sections ( $5-\mu \mathrm{m}$ thick) were then stained with hematoxylin and eosin or with Masson's Trichrome stain. Lung injury score was calculated under a light microscope by two qualified investigators blinded to samples according to the weighted scale guideline ${ }^{12}$.

\section{Western blotting analysis (in vivo)}

Using PRO-PREP Extraction Solution (600 $\mu$ L, Cat. \# 17081, iNtRON Biotechnology, Seongnam, Korea), the excised frozen right lungs ( $10 \mathrm{mg}$ ) were mechanically homogenized, lysed by incubation for $20-30$ minutes in a freezer at $-20^{\circ} \mathrm{C}$, and then centrifuged at $13,000 \times \mathrm{g}$ for 30 minutes at $4^{\circ} \mathrm{C}$. Equal aliquots of protein were resolved on SDS-PAGE and transferred to nitrocellulose membranes. The membranes were probed with TGF- $\beta 1$ (Calbiochem), Smad3 (Millipore Technologies, Billerica, MA, USA), and $\alpha$-tubulin (Cell Signaling Technology), labeled with anti-rabbit or anti-goat IgG conjugated to horseradish peroxidase, and visualized using a Super-Signal West Pico Chemiluminescence Detection Kit (Pierce, Rockford, IL, USA). Band densities were measured by the Alpha Ease FC software version 4.1.0 (Innotech, San Leandro, CA, USA). Images were analyzed semi-quantitatively using NIH Image J.

\section{Hydroxyproline assay}

The amount of collagen in the left lung was measured using a hydroxyproline assay kit (Cell Biolabs, San Diego, CA, USA). Lung tissue was homogenized in $100 \mathrm{~mL}$ of distilled water, and hydrolyzed in $100 \mu \mathrm{L} 12 \mathrm{~N} \mathrm{HCl}$ for 3 hours at $120^{\circ} \mathrm{C}$. The hydrolyzed samples were mixed with $5 \mathrm{mg}$ of activated charcoal, and centrifuged at $10,000 \times \mathrm{g}$ for 5 minutes at $4^{\circ} \mathrm{C}$. The absorbance of hydroxyproline content was determined at a wavelength of $540 \mathrm{~nm}$, and absolute values were determined from a standard curve.

\section{Statistical analysis}

Continuous variables were compared by a Mann-Whitney $\mathrm{U}$ test. An adjusted $\mathrm{p}$-value of $<0.05$ was significant. SPSS version 22.0 (IBM Corp., Armonk, NY, USA) was used for all statistical analyses.

\section{Results}

\section{TGF- $\beta_{1}$ induced Smad2/3 phosphorylation}

To understand the early molecular mechanism involved in the TGF- $\beta 1$ induced phosphorylation of Smad, the phosphorylation of Smad2/3 was examined using a phospho-specific antibody. TGF- $\beta 1$ stimulation induced the phosphorylation of Smad2/3 in A549 cells. Time-course analysis revealed that the phosphorylation of Smad2/3 was detected 15 minutes after TGF- $\beta 1$ stimulation and lasted for 24 hours. The phosphoryla- 


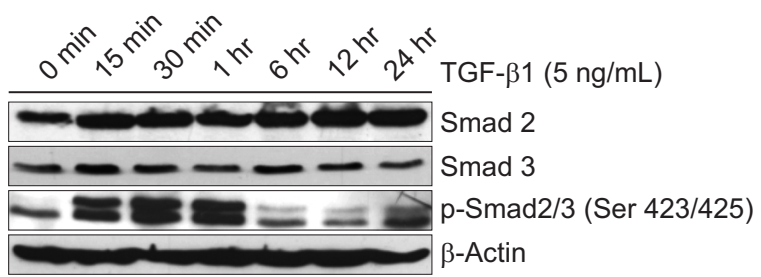

Figure 1. Time-dependent phosphorylation of Smad2/3 induced by TGF- $\beta 15$ ng/mL. After stimulation with 5 ng/mL TGF- $\beta 1$, A549 cells were incubated for the indicated times, and the reactive proteins were electrophoresed on a 10\% SDS-PAGE gel. The protein levels of Smad2/3 and p-Smad2/3 were analyzed by western blot. The phosphorylation of Smad2/3 reached a peak 1 hour following TGF- $\beta 1$ stimulation. TGF- $\beta 1$ : transforming growth factor $\beta 1$; SDSPAGE: sodium dodecyl sulfate polyacrylamide gel electrophoresis gel. tion of Smad2/3 in A549 cells reached its peak at 1 hour following TGF- $\beta 1$ stimulation (Figure 1).

\section{The effects of Smad phosphorylation by RA and TGF- $\beta 1$ stimulation}

To examine the dose-dependent effects of RA on the activation of Smad, RAs were dissolved in DMSO (final concentration in culture medium was $0.1 \%$ ) and the final concentrations of the RAs were $10^{-7}, 10^{-6}$, and $10^{-5} \mathrm{~mol} / \mathrm{L}$. A549 cells were incubated with FBS-free RPMI alone or in the presence of various concentrations of each RA for 48 hours. They were subjected to western blotting to identify Smad2/3. The optimal RA concentration was $10^{-6} \mathrm{~mol} / \mathrm{L}$ (Figure 2 ).

Following TGF- $\beta 1$ stimulation, both $\operatorname{Smad} 2 / 3$ and $\mathrm{p}$ -
A

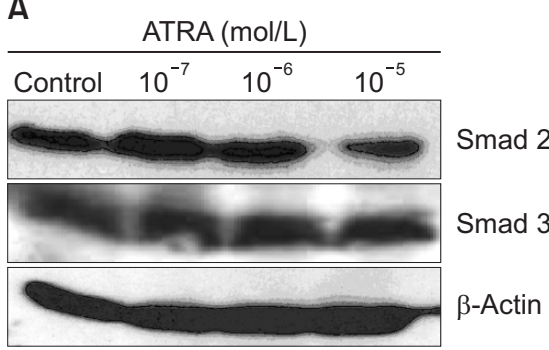

B

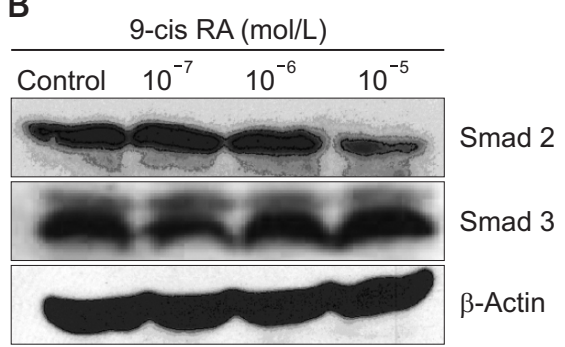

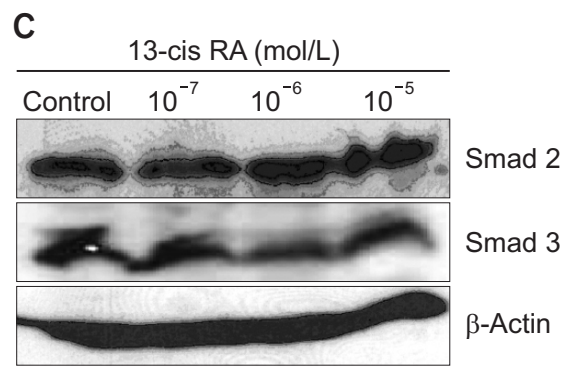

Figure 2. Representative results of Smad expression by western blot according to concentration of ATRA (A), 9-cis RA (B), and 13-cis RA (C) stimulation. After stimulation with various concentrations of the three RAs, A549 cells were incubated for 24 hours and then electrophoresed on a 10\% SDS-PAGE gel. Expression of Smad2 and Smad3 protein was analyzed by western blot. The optimal concentration of the RAs was $10^{-6} \mathrm{~mol} / \mathrm{L}$, stimulating the maximum expression of Smad2 and Smad3. ATRA: all-trans retinoic acid; RA: retinoic acid; SDS-PAGE: Sodium dodecyl sulfate polyacrylamide gel electrophoresis gel.

A

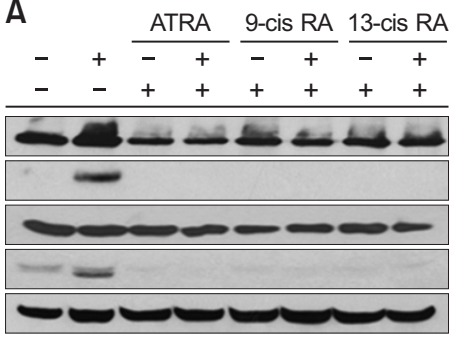

: TGF- $\beta 1$$$
\text { RA }
$$

Smad 2

p-Smad2 (Ser 465/467)

Smad 3

p-Smad3 (Ser 423/425)

$\beta$-Actin

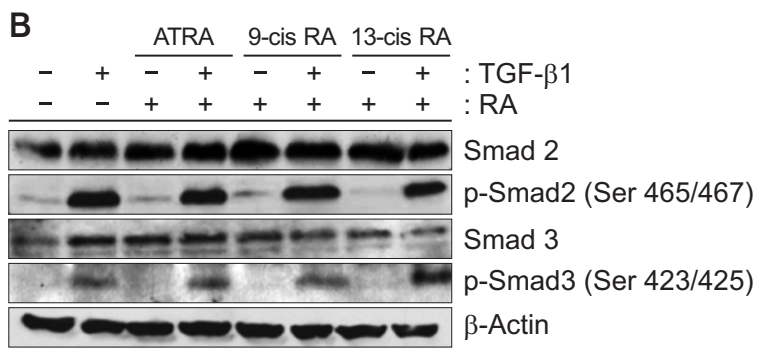

Figure 3. (A) Representative results of Smad expression by western blot upon pre-stimulation with TGF- $\beta 1$ followed by administration of each of the three RAs. A549 cells were left untreated (control) or stimulated with one of the following conditions: TGF- $\beta 1$ alone, each of the three RAs alone, or pre-stimulated with TGF- $\beta 1$ followed by administration of one of the three retinoic acids. They were incubated for 24 hours and electrophoresed on a 10\% SDS-PAGE gel. The levels of Smad2/3 and p-Smad2/3 were analyzed by western blot. TGF- $\beta 1$ activated Smad2/3 and increased p-Smad2/3. In contrast, RA administration completely inhibited the phosphorylation of Smad2/3. This was similarly observed under conditions of pre-stimulated and simultaneous TGF- $\beta 1$ administration followed by treatment with the three RAs. (B) Representative results of Smad expression by western blot upon pre-treatment with RA followed by TGF- $\beta 1$ stimulation. A549 cells were left untreated (control) or stimulated with one of the following conditions: TGF- $\beta 1$ alone, each of the three RAs alone or pre-treatment with each of the RAs followed administration of TGF- $\beta 1$. The cells were incubated for 24 hours and electrophoresed on a 10\% SDS-PAGE gel. The levels of Smad $2 / 3$ and $p$-Smad2/3 were analyzed by western blot. TGF- $\beta 1$ activated Smad $2 / 3$ and increased p-Smad2/3. RA treatment completely inhibited the phosphorylation of Smad2/3. However, when pre-treated RA was administered, followed by TGF- $\beta 1$ stimulation, RAs did not suppress the phosphorylation of Smad2/3. TGF- $\beta 1$ : transforming growth factor $\beta 1$; ATRA: all-trans retinoic acid; RA: retinoic acid; SDS-PAGE: sodium dodecyl sulfate polyacrylamide gel electrophoresis gel. 
Smad2/3 were increased compared with the control A549 cells. Each of the three RAs $\left(10^{-6} \mathrm{~mol} / \mathrm{L}\right)$, ATRA, 9-cis RA, and 13-cis RA, elicited a similar effect on Smad phosphorylation. The RAs selectively inhibited the phosphorylation of Smad2/3. When cells were pre-stimulated with TGF- $\beta 1$ and then treated with the three RAs, the phosphorylation of Smad2/3 was completely abrogated (Figure $3 \mathrm{~A}$ ).

However, when the cells were stimulated with each of the RAs before TGF- $\beta 1$, different results were observed. After stimulation with TGF- $\beta 1$, the RAs completely inhibited the phosphorylation of Smad2/3, but when the cells were pre- treated with RA and then stimulated with TGF- $\beta 1$, the phosphorylation of Smad2/3 was not completely suppressed (Figure 3B).

\section{Effects of ATRA and MAPK inhibitors differ between A549 epithelial cells and CCD-11 Lu fibroblasts}

Similar to the A549 epithelial cells, TGF- $\beta 1$ significantly increased p-Smad2/3 expression in CCD-11Lu fibroblasts, and this effect was completely suppressed by administration of the ATRA. However, when these cells were pre-treated with each
A
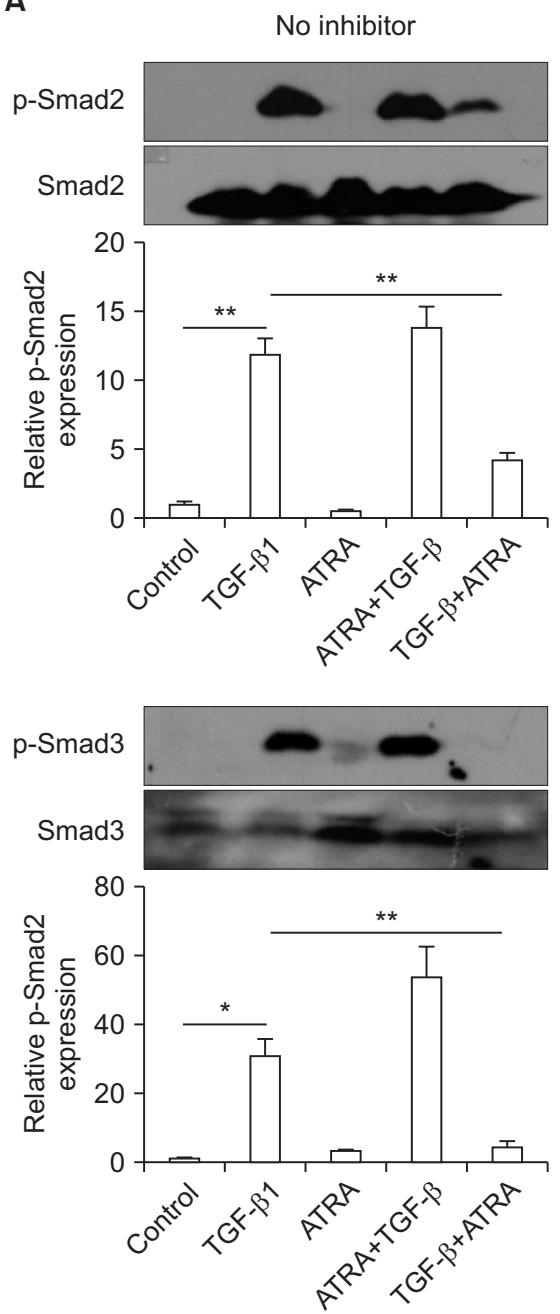

B
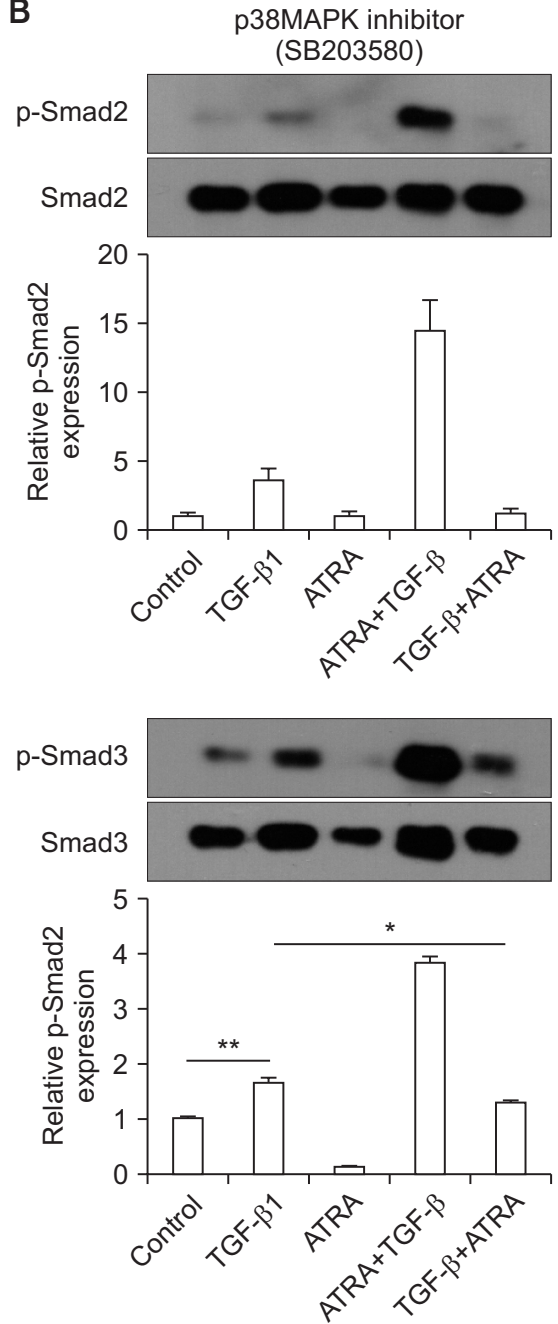

C
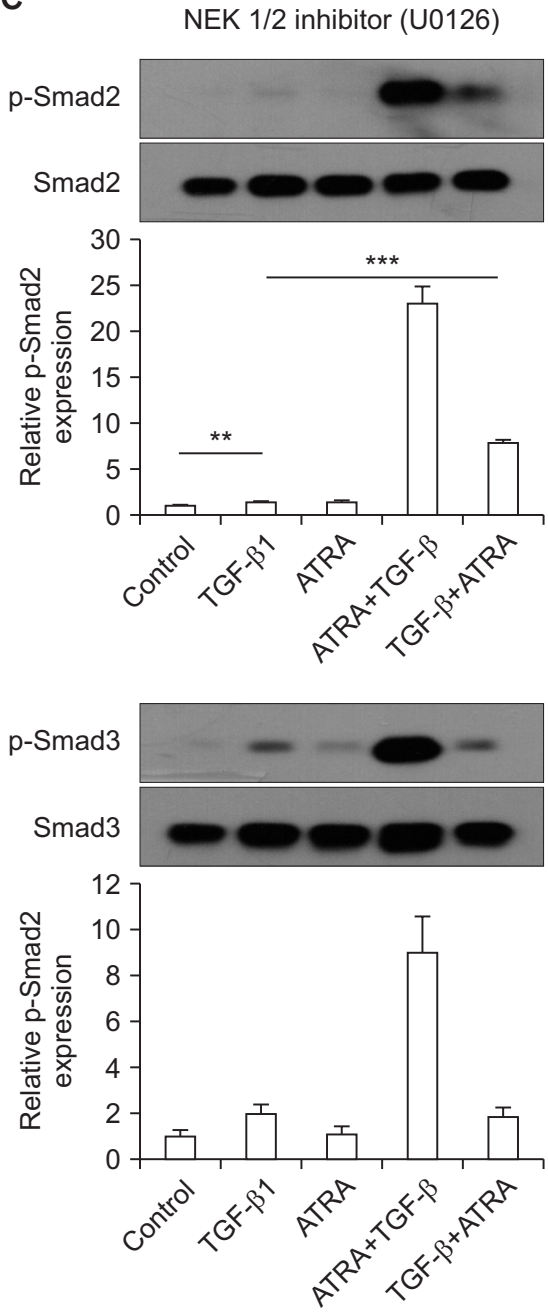

Figure 4. (A-C) Representative western blot results of A549 epithelial cell Smad expression upon pre-treatment with a p38 MAPK inhibitor (B) or a MEK inhibitor (C). A549 cells were pre-treated with a p38 MAPK inhibitor or a MEK inhibitor, and then the cells were stimulated as follows: (1) control, (2) TGF- $\beta 1$, (3) RA (ATRA), (4) pre-treated with RA (ATRA) prior to TGF- $\beta 1$ stimulation, or (5) pre-stimulated with TGF- $\beta 1$ prior to RA (ATRA) treatment. The cells were then incubated for 24 hours and electrophoresed on a 10\% SDS-PAGE gel. The levels of Smad2/3 and p-Smad2/3 expression were analyzed by western blot. TGF- $\beta 1$ did not significantly elevate p-Smad 2 expression when epithelial cells were pre-treated with the p38 MAPK inhibitor. When epithelial cells were pre-treated with the MEK 1/2 inhibitor, p-Smad3 expression was not significantly increased by TGF- $\beta 1$. MAPK: mitogen-activated protein kinase; TGF- $\beta 1$ : transforming growth factor $\beta 1$; RA: retinoic acid; ATRA: all-trans retinoic acid; SDS-PAGE: sodium dodecyl sulfate polyacrylamide gel electrophoresis gel. ${ }^{*} \mathrm{p}<0.05,{ }^{* *} \mathrm{p}<0.01,{ }^{* * *} \mathrm{p}<0.001$. 
A
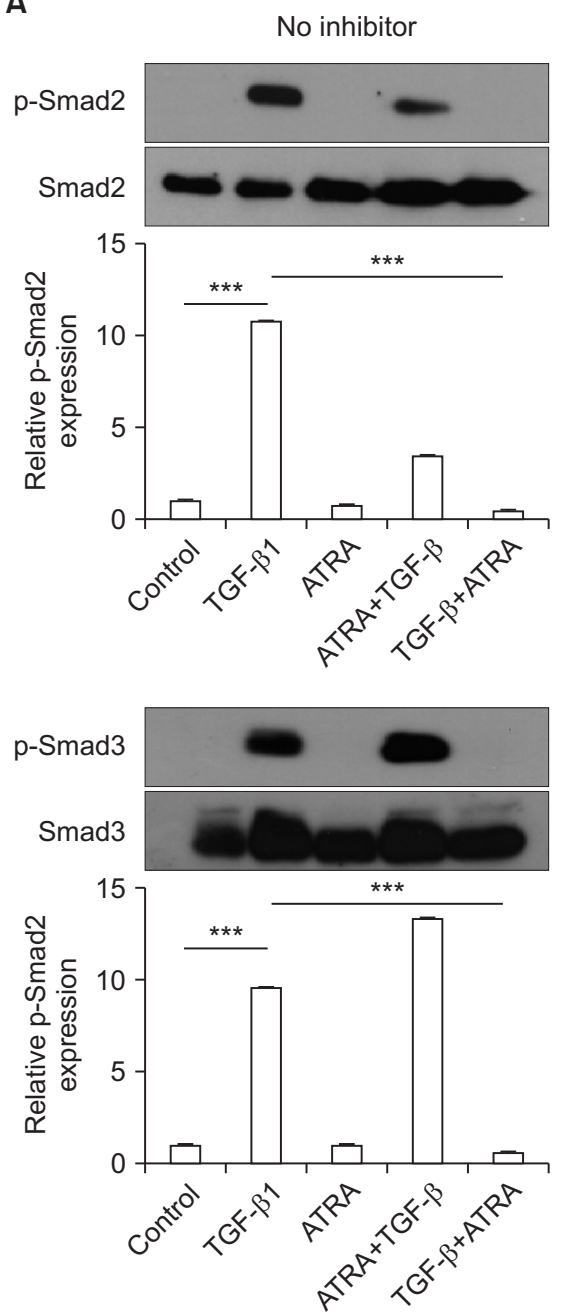

B
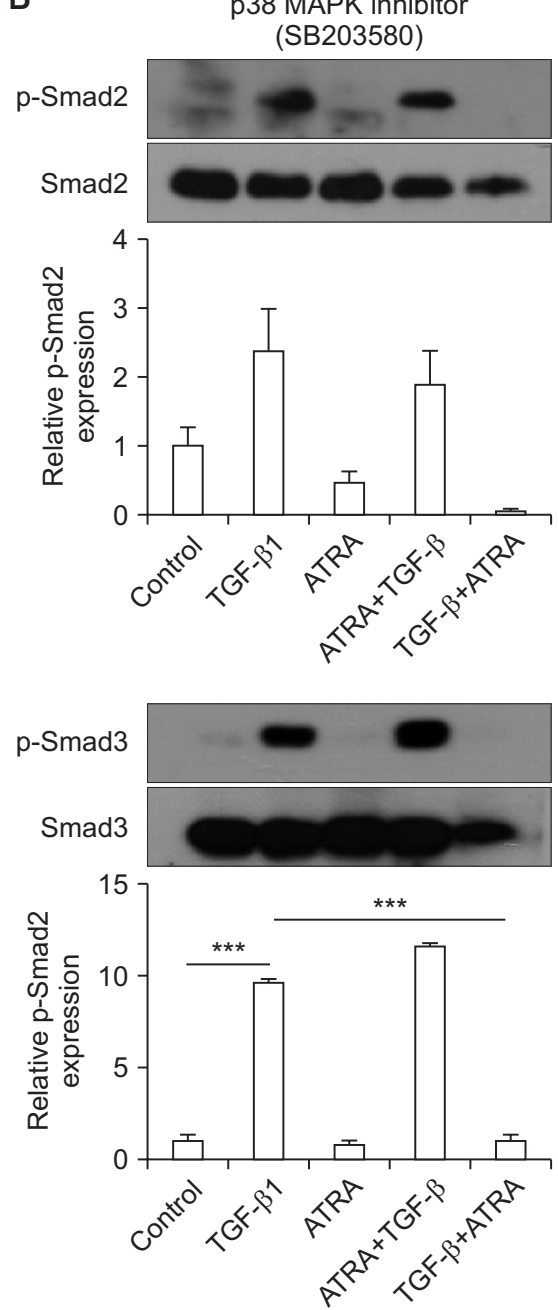

C
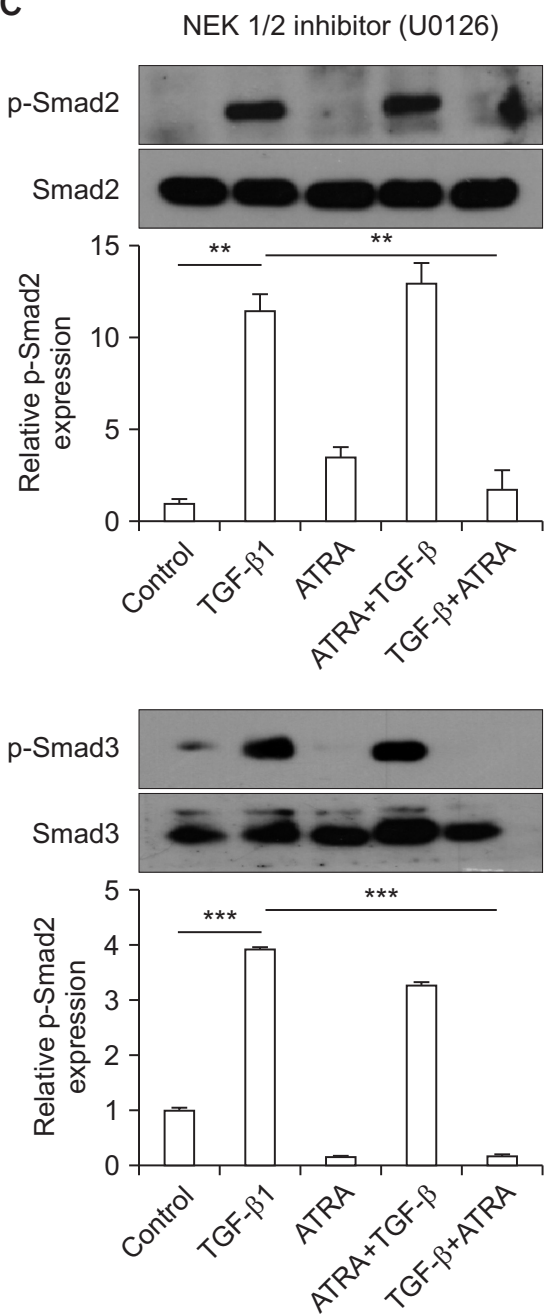

Figure 5. (A-C) Representative western blot results of CCD-11Lu fibroblast cell Smad expression upon pre-treatment with a p38 MAPK inhibitor (B) or a MEK inhibitor (C). CCD-11Lu cells were pre-treated with a 338 MAPK inhibitor or a MEK inhibitor, and then cells were stimulated as follows: (1) control, (2) TGF- $\beta 1$, (3) RA (ATRA), (4) pre-treated with RA (ATRA) prior to TGF- $\beta 1$ stimulation, or (5) pre-stimulated with TGF- $\beta 1$ prior to RA (ATRA) treatment. CCD-11Lu cells were then incubated for 24 hours and electrophoresed on a 10\% SDS-PAGE gel. The levels of Smad2/3 and p-Smad2/3 expression were analyzed by western blot. In fibroblasts pre-treated with the p38 MAPK inhibitor, TGF- $\beta 1$ did not significantly increase p-Smad2 expression. MAPK: mitogen-activated protein kinase; TGF- $\beta 1$ : transforming growth factor $\beta 1$; RA: retinoic acid; ATRA: all-trans retinoic acid; SDS-PAGE: sodium dodecyl sulfate polyacrylamide gel electrophoresis gel. ${ }^{* *} \mathrm{p}<0.01,{ }^{* * *} \mathrm{p}<0.001$.

of the ATRA, followed by TGF- $\beta 1$ administration, suppression of $\mathrm{p}$-Smad2/3 expression was not observed (Figures 4A, $5 \mathrm{~A}$ ).

To compare the effects of ATRA and MAPK inhibitors on the phosphorylation of $S$ mad $2 / 3$ induced by TGF- $\beta 1$ between A549 epithelial cells and CCD-11Lu fibroblasts, the cell lines were pre-treated with a p38 MAPK inhibitor (SB203580; 6 $\mu \mathrm{M}$ for 30 minutes) or a MEK 1/2 inhibitor (U0126; $10 \mu \mathrm{M}$ for 30 minutes) prior to administration of RA and/or TGF- $\beta 1$ (Figures 4B, C, 5B, C). TGF- $\beta 1$ administration increased pSmad2/3 levels, both in A549 and CCD-11Lu cells. However, there were some differences between A549 and CCD-11Lu cells when they were pre-treated with the p38 MAPK inhibi- tor. In A549 cells, TGF- $\beta 1$ did not increase p-Smad2 levels. Additionally, p-Smad2/3 levels in A549 cells pre-treated with the p38 MAPK inhibitor, followed by administration of TGF- $\beta 1$, were lower than those in the cells that were not pre-treated. A549 cells pre-treated with the MEK $1 / 2$ inhibitor showed stable p-Smad3 levels. Although TGF- $\beta 1$ treatment elevated the levels of p-Smad2 significantly in A549 cells pre-treated with the MEK 1/2 inhibitor, p-Smad2 levels were lower than those in the cells that were not pre-treated.

In CCD-11Lu cells, regardless of pre-treatment with MAPK inhibitors, TGF- $\beta 1$ increased p-Smad3 levels. p-Smad2 levels, however, were not increased in response to pre-treatment 
with the p38 MAPK inhibitor.

\section{ATRA attenuates bleomycin-induced lung injury and fibrosis in mouse model}

As shown in Figures 6 and 7, bleomycin treatment significantly induced lung injury after both 1 week $(\mathrm{p}<0.05)$ and 3 weeks $(\mathrm{p}<0.001)$, and ATRA significantly attenuated the lung injury at 3 weeks. At 1 week, the TGF- $\beta$ and Smad3 levels in the bleomycin group were significantly increased compared with those in the control group $(\mathrm{p}<0.01$ for both levels), but subsequent treatment with $0.5 \mathrm{mg}$ ATRA significantly blocked this increase $(\mathrm{p}<0.001$ for both levels) (Figure 8). However, at 3 weeks, neither TGF- $\beta$ nor Smad3 levels were significantly increased in the bleomycin group. ATRA only significantly blocked the increase of TGF- $\beta$ levels $(\mathrm{p}<0.001)$, failing to significantly block Smad3 levels (Figure 9).

\section{Discussion}

In this study, we demonstrated that RA inhibits the phosphorylation of Smad2/3 induced by TGF- $\beta 1$ in both epithelial cells and fibroblasts. In addition, the inhibition of Smad2/3 phosphorylation using RA was clearly demonstrated in cells pre-treated with TGF- $\beta 1$. This implies that RA may have an inhibitory effect on the progression of pulmonary fibrosis in patients who demonstrate activation and over-stimulation
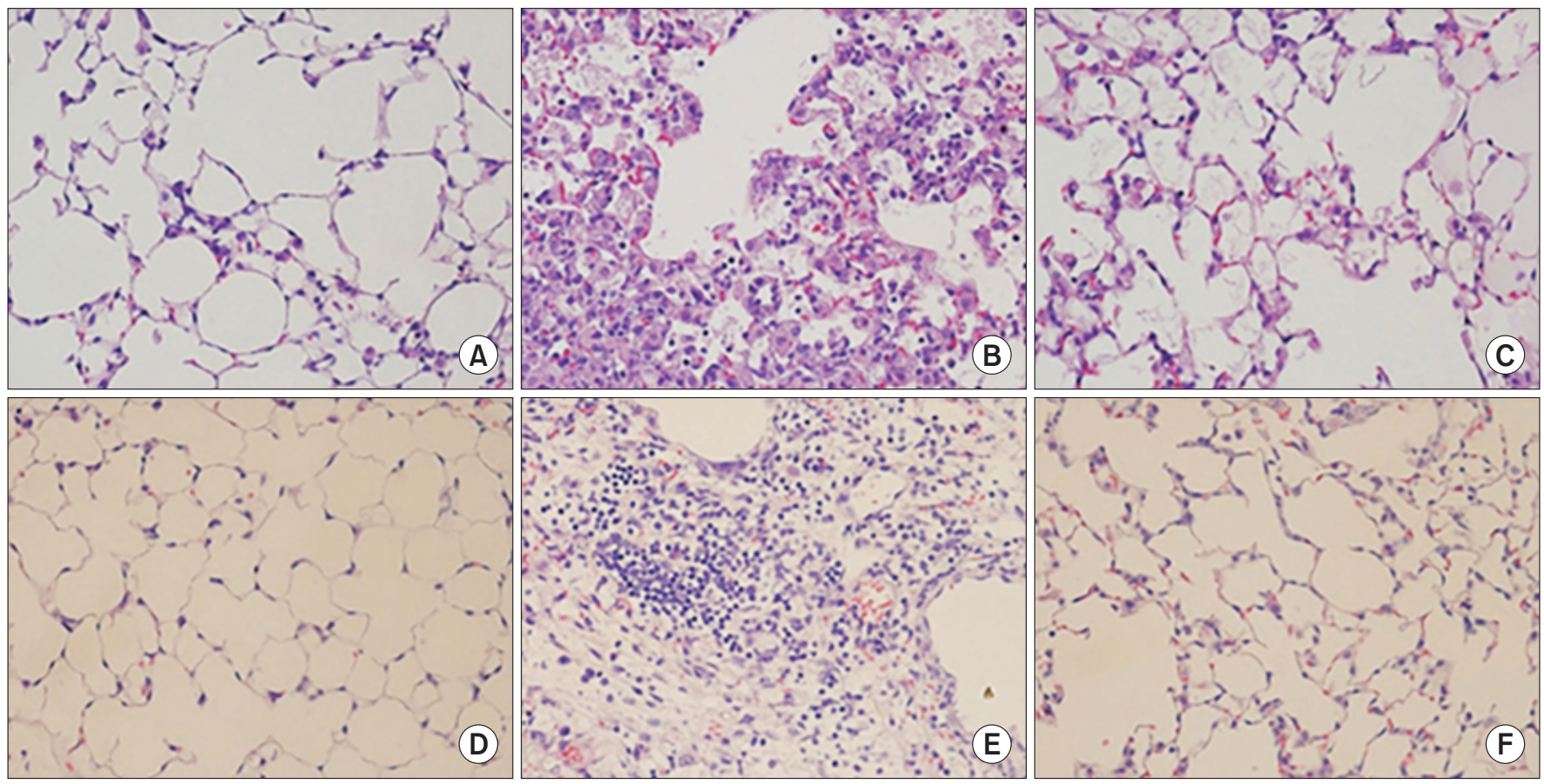

G

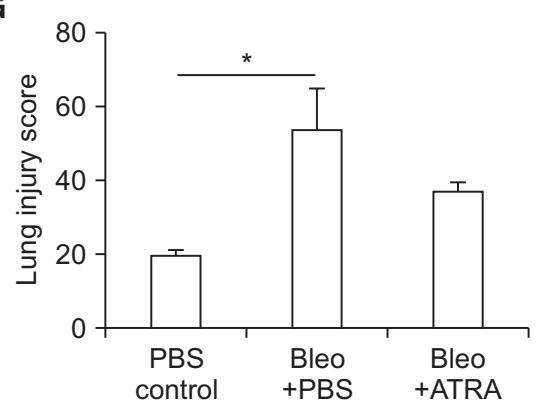

$\mathrm{H}$

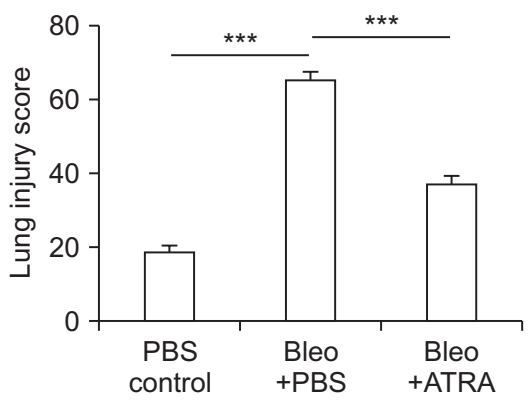

Figure 6. Histological sections of lung fields stained with hematoxylin and eosin $(A-F, \times 400)$ and lung injury score $(G, H)$ for the following treatments and at the specified timepoints: control at 1 week (A), bleomycin at 1 week (B), bleomycin followed by ATRA at 1 week (C), control at 3 weeks (D), bleomycin at 3 weeks (E), bleomycin followed by ATRA at 3 weeks (F), lung injury score at 1 week (G), and at 3 weeks (H). Bleomycin-induced lung damage and ATRA attenuates the lung injury. ATRA: all-trans retinoic acid; PBS: phosphate buffered saline; Bleo: bleomycin. ${ }^{*} \mathrm{p}<0.05,{ }^{* * *} \mathrm{p}<0.001$. 

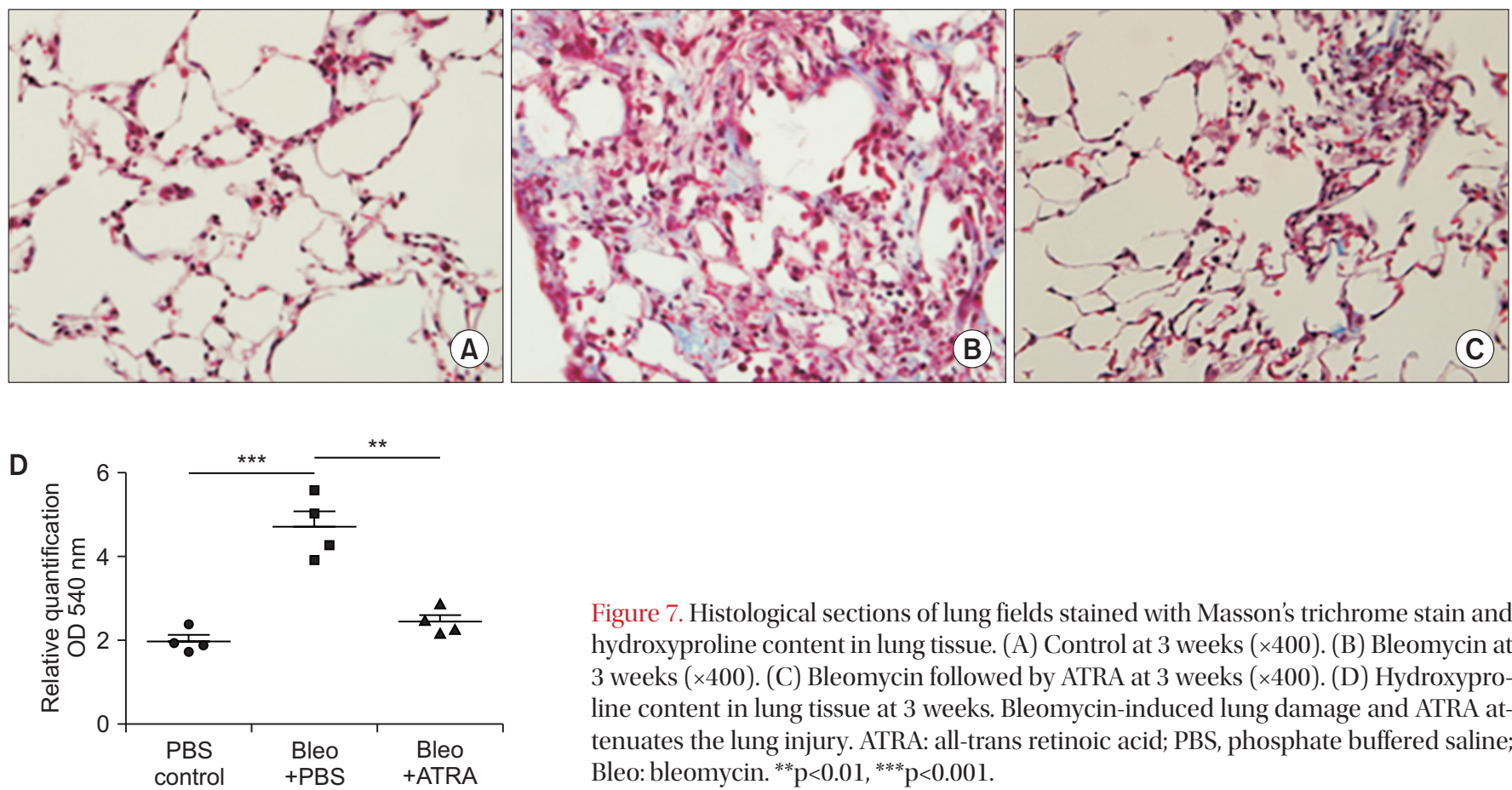

Figure 7. Histological sections of lung fields stained with Masson's trichrome stain and hydroxyproline content in lung tissue. (A) Control at 3 weeks $(\times 400)$. (B) Bleomycin at 3 weeks $(\times 400)$. (C) Bleomycin followed by ATRA at 3 weeks $(\times 400)$. (D) Hydroxyproline content in lung tissue at 3 weeks. Bleomycin-induced lung damage and ATRA attenuates the lung injury. ATRA: all-trans retinoic acid; PBS, phosphate buffered saline; Bleo: bleomycin. ${ }^{* *} \mathrm{p}<0.01,{ }^{* * *} \mathrm{p}<0.001$.

of TGF- $\beta 1$, but not a preventative effect. This phenomenon was also investigated in a bleomycin-induced lung injury and fibrosis mouse model at 1 and 3 weeks. Furthermore, we demonstrated the inhibitory effect of pre-treatment with the p38 MAPK and MEK inhibitors on Smad phosphorylation induced by TGF- $\beta 1$, and outlined differences in the effects on epithelial cells and fibroblasts. Our study suggests that a combination of MAPK inhibitors and ATRA may exert preventative and inhibitory effects on pulmonary fibrosis.

There is evidence that interactions between RA and TGF- $\beta$ play important roles in cellular proliferation and differentiation, including modulation of the balance between these two processes $^{13}$.

The effects of RA on pulmonary fibrosis have been investigated, and RA has been shown to inhibit TGF- $\beta 1$-induced collagen production from human lung fibroblasts, as well as from both idiopathic pulmonary fibrosis and neonatal lung fibroblasts $^{14,15}$. The inhibitory effects of RA on TGF- $\beta 1$ are closely related to the phosphorylation of Smad $3^{16,17}$. A study demonstrated that ATRA prevents radiation- or bleomycininduced pulmonary fibrosis through reduced production of interleukin 6, TGF- $\beta 1$, and collagen from human fetal lung fibroblasts ${ }^{18}$. These data may provide the rationale for exploring the clinical use of ATRA for the prevention of radiationinduced pulmonary fibrosis and other pathologic conditions involving pulmonary fibrosis.

It has been shown that RA induced hypochondrogenesis through regulation of the TGF- $\beta 1$ pathway, suggesting a role for TGF- $\beta$ receptor II (T $\beta$ RII)/Smad in retinoid-induced cleft palate $^{19}$. In contrast to embryonic cells, RA increased ${ }^{8,20}$ or decreased $^{21}$ expression of TGF- $\beta 1$ in leukemic cells. TGF- $\beta 1$ in combination with ATRA acted synergistically to inhibit growth, and to stimulate apoptosis of these cells. The results for the effects of RA on the expression of TGF- $\beta 1$ are conflicted; depending on cell type, culture conditions, and type of RA used, both elevations and reductions have been reported. This study demonstrated that RAs completely inhibited the phosphorylation of Smad2/3 in the presence of RA alone and when pre-stimulated with TGF- $\beta 1$ followed by administration of RA. However, RAs did not completely suppress the phosphorylation of Smad2/3 when cells were pre-treated RA followed TGF- $\beta 1$ stimulation. In our study, epithelial cells that were pre-treated with RA followed TGF- $\beta 1$ stimulation showed greater phosphorylated $\operatorname{Smad} 2 / 3$ expression than TGF- $\beta 1$ stimulated epithelial cells that were not pre-treated with RA. This might be the result of a different spatiotemporal status of pre-stimulation because cells pre-treated with RA have a higher responsiveness to T $\beta R I I$ induction to exogenous TGF- $\beta 1$ administration, as was observed in HL-60 leukemic cells $^{22}$, where the induction of T $\beta$ RII led to an increased response to exogenous TGF- $\beta 1$ and increased phosphorylation of $\operatorname{Smad} 2 / 3$.

In contrast, it might be the result of other mechanisms of Smad phosphorylation. TGF- $\beta 1$ was shown to activate the PI3K and ERK pathways, which led to Smad3 phosphorylation at the linker region in rat myofibroblasts ${ }^{23}$. Additional studies are needed to elucidate the effects of RA on the various mechanisms of the TGF- $\beta 1$ signal transduction pathway, and 
A

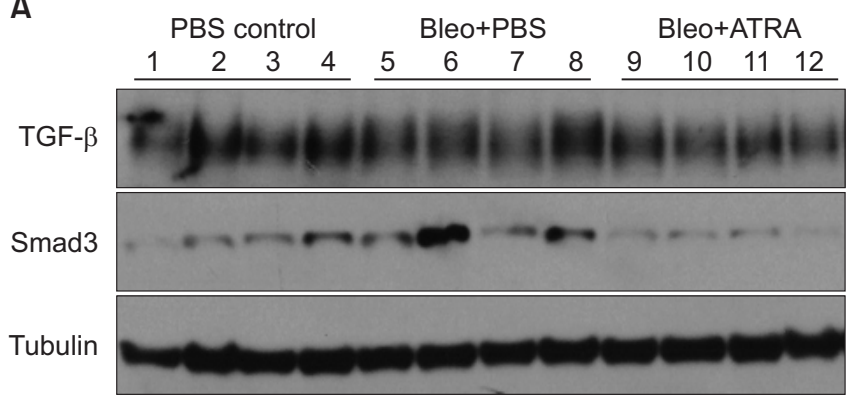

B

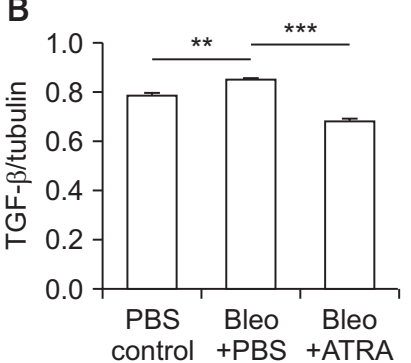

C

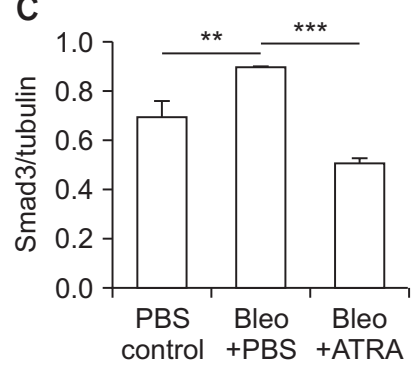

Figure 8. (A-C) Expression of TGF- $\beta$ and Smad3 in lung lysates upon treatment with bleomycin followed by ATRA, as measured by densitometry at 1 week for TGF- $\beta$ (B) and Smad3 (C). Male C57BL/6J mice were stimulated as follows: (1) control, (2) bleomycin, or (3) bleomycin followed by ATRA. Bleomycin significantly increased the levels of TGF- $\beta$ and Smad3, and ATRA significantly decreased the levels of TGF- $\beta$ and Smad 3 at 1 week. TGF- $\beta$ : transforming growth factor $\beta$; ATRA: all-trans retinoic acid; PBS: phosphate buffered saline; Bleo: bleomycin. ${ }^{* *} \mathrm{p}<0.01,{ }^{* * *} \mathrm{p}<0.001$.

on the various target genes that promote fibrosis, apoptosis, and epithelial-mesenchymal transition (EMT).

Many studies have indicated that unregulated recovery of epithelial injury is the beginning and cause of pulmonary fibrosis pathogenesis ${ }^{1,24,25}$. Ross et al. ${ }^{26}$ demonstrated that Smad3 expression is regulated by mitogen-activated protein kinase kinase-1 (MEK1) in epithelial and smooth muscle cells. p-Smad3 was not increased in epithelial cells in our study upon pre-treatment with a MEK $1 / 2$ inhibitor (Figure 4C). However, in fibroblasts pre-treated with the MEK $1 / 2$ inhibitor, the effect of TGF- $\beta 1$ was not inhibited (Figure 5C). Our study demonstrated that pre-treatment with MAPK inhibitors was effective in preventing the effect of TGF- $\beta 1$ on epithelial cells.

Through Smad or non-Smad pathway and extracellular stimuli, TGF- $\beta$ activate all ERK, p38 MAPK, and JNK MAPK ${ }^{27}$. In our study, pre-treatment of epithelial cells and fibroblast with a 38 MAPK inhibitor showed a non-significant response to TGF- $\beta 1$ in p-Smad2. Although TGF- $\beta 1$ also significantly elevated $\mathrm{p}$-Smad3 expression, regardless of pre-treatment with the p38 MAPK inhibitor, the levels of expression were lower in the absence of the inhibitor. Therefore, the p38 MAPK inhibitor could be effective against both Smad2 and Smad3 phosphorylation.

A

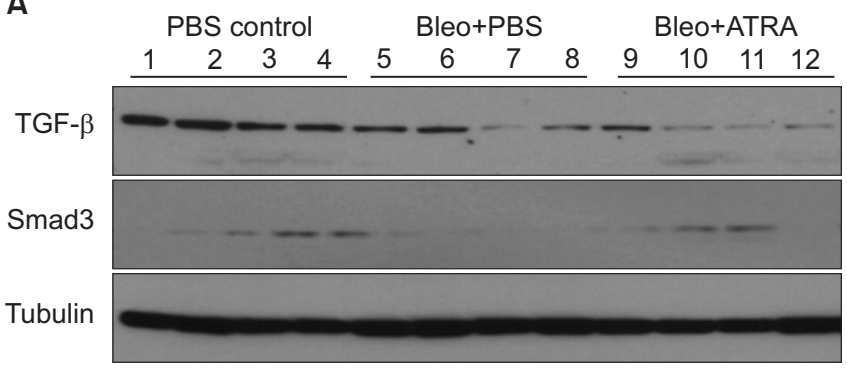

B

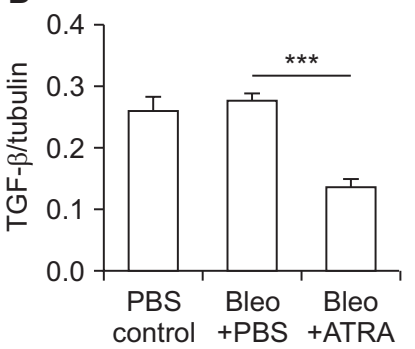

C

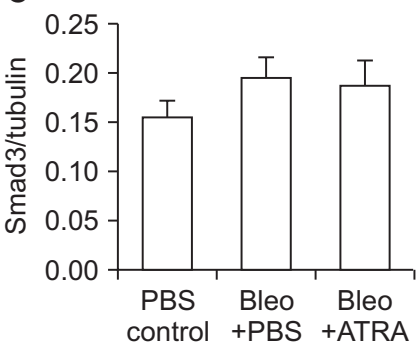

Figure 9. (A-C) Expression of TGF- $\beta$ and Smad3 in lung lysates upon treatment with bleomycin followed by ATRA, as measured by densitometry at 3 weeks for TGF- $\beta$ (B) and Smad3 (C). Male C57BL/6J mice were stimulated as follows: (1) control, (2) bleomycin, or (3) bleomycin followed by ATRA. ATRA decreased the levels of TGF- $\beta$ at 3 weeks but not of Smad3. TGF- $\beta$ : transforming growth factor $\beta$; ATRA: all-trans retinoic acid; PBS: phosphate buffered saline; Bleo: bleomycin. ${ }^{* * *} \mathrm{p}<0.001$.

Previous studies have demonstrated that TGF- $\beta 1$ is associated with MAPK signaling and EMT induction ${ }^{28,29}$. Through EMT, epithelial cells might be converted to myofibroblasts ${ }^{30}$. Abnormal activated alveolar epithelial cells are important mediators that induce the formation of fibroblast and myofibroblast foci, which secrete excessive amounts of collagen, resulting in scarring and compromised lung function ${ }^{31}$. In our study, both fibroblasts and epithelial cells pre-treated with MAPK inhibitors showed significant decreases in Smad2 phosphorylation. Additionally, ATRA was shown to be effective in both epithelial cells and fibroblasts, pre-treated with a MAPK inhibitor, in suppressing p-Smad3. Furthermore, bleomycin-induced lung injury and fibrosis was reduced in vivo by ATRA in our study. At 1 week, TGF- $\beta$ and Smad3 levels were increased by bleomycin treatment and decreased by subsequent treatment with ATRA. At 3 weeks, TGF- $\beta$ and Smad3 levels showed increases similar to those shown at 1 week, but only the levels of TGF- $\beta$ were significantly reduced by ATRA. This could be explained by the possibility that, while TGF- $\beta$ and Smad3 play important roles in bleomycin-induced lung damage at 1 week, other pathways might exist in lung injury after 1 week. Shi et al. ${ }^{32}$ showed that the signal of TGF- $\beta$ was significantly stronger than that in the control group in an animal model within 2 weeks, and the signal of TGF- $\beta$ was weaker later, as observed in our results. Additional experiments are needed to 
confirm the role of ATRA and MAPK inhibitors in bleomycininduced lung fibrosis according to time change. Therefore, early treatment with RA and MAPK inhibitors could be of use in preventing and inhibiting the effect of TGF- $\beta 1$ in both epithelial cells and fibroblasts. In addition, as shown in the mouse experiment, mechanisms of treatment other than ATRA are needed to lower the level of Smad.

In conclusion, our observations suggest that interactions between RA and TGF- $\beta 1$ signal transduction pathways may, thus, provide a variety of mechanisms by which subtle alterations in p-Smad expression. Administration of combinations of RA and MAPK inhibitors had inhibitory effects on the phosphorylation of Smad $2 / 3$ induced by TGF- $\beta 1$.

\section{Authors' Contributions}

Conceptualization: Lee SH, Park MS. Methodology: Park MS, Shin JH, Shin MH. Formal analysis: all authors. Data curation: Shin JH, Shin MH. Validation: Lee SH, Park MS, Shin JH, Shin MH. Investigation: Park MS, Kim YS, Chung KS, Song JH, Kim SY, Kim EY, Jung JY, Kang YA, Chang J. Writing - original draft preparation: Lee SH, Park MS. Writing - review and editing: Park MS, Kim YS, Chung KS, Song JH, Kim SY, Kim EY, Jung JY, Kang YA, Chang J. Approval of final manuscript: all authors.

\section{Conflicts of Interest}

No potential conflict of interest relevant to this article was reported.

\section{Acknowledgments}

This study was supported by a faculty research grant of Yonsei University College of Medicine for 2008 (No. 6-2008-0150).

\section{References}

1. Selman M, King TE, Pardo A; American Thoracic Society; European Respiratory Society; American College of Chest Physicians. Idiopathic pulmonary fibrosis: prevailing and evolving hypotheses about its pathogenesis and implications for therapy. Ann Intern Med 2001;134:136-51.

2. Gross TJ, Hunninghake GW. Idiopathic pulmonary fibrosis. N Engl J Med 2001;345:517-25.

3. Lepparanta O, Sens C, Salmenkivi K, Kinnula VL, Keski-Oja J, Myllarniemi M, et al. Regulation of TGF- $\beta$ storage and activation in the human idiopathic pulmonary fibrosis lung. Cell Tissue Res 2012;348:491-503.
4. Gu L, Zhu YJ, Guo ZJ, Xu XX, Xu WB. Effect of IFN-gamma and dexamethasone on TGF-betal-induced human fetal lung fibroblast-myofibroblast differentiation. Acta Pharmacol Sin 2004;25:1479-88.

5. Wen FQ, Liu X, Kobayashi T, Abe S, Fang Q, Kohyama T, et al. Interferon-gamma inhibits transforming growth factorbeta production in human airway epithelial cells by targeting Smads. Am J Respir Cell Mol Biol 2004;30:816-22.

6. Wang J, Yang Y, Xu J, Lin X, Wu K, Yu M. Pirfenidone inhibits migration, differentiation, and proliferation of human retinal pigment epithelial cells in vitro. Mol Vis 2013;19:2626-35.

7. Zhang YE. Non-Smad pathways in TGF- $\beta$ signaling. Cell Res 2009;19:128-39.

8. Pendaries V, Verrecchia F, Michel S, Mauviel A. Retinoic acid receptors interfere with the TGF- $\beta /$ Smad signaling pathway in a ligand-specific manner. Oncogene 2003;22:8212-20.

9. Rhinn M, Dolle P. Retinoic acid signalling during development. Development 2012;139:843-58.

10. Barber T, Esteban-Pretel G, Marin MP, Timoneda J. Vitamin a deficiency and alterations in the extracellular matrix. Nutrients 2014;6:4984-5017.

11. Bastien J, Rochette-Egly C. Nuclear retinoid receptors and the transcription of retinoid-target genes. Gene 2004;328:1-16.

12. Matute-Bello G, Downey G, Moore BB, Groshong SD, Matthay MA, Slutsky AS, et al. An official American Thoracic Society workshop report: features and measurements of experimental acute lung injury in animals. Am J Respir Cell Mol Biol 2011;44:725-38.

13. Mahmood R, Flanders KC, Morriss-Kay GM. Interactions between retinoids and TGF beta $\mathrm{s}$ in mouse morphogenesis. Development 1992;115:67-74.

14. Redlich CA, Delisser HM, Elias JA. Retinoic acid inhibition of transforming growth factor-beta-induced collagen production by human lung fibroblasts. Am J Respir Cell Mol Biol 1995;12:287-95.

15. Torry DJ, Richards CD, Podor TJ, Gauldie J. Modulation of the anchorage-independent phenotype of human lung fibroblasts obtained from fibrotic tissue following culture with retinoid and corticosteroid. Exp Lung Res 1996;22:231-44.

16. Zhao Y, Geverd DA. Regulation of Smad3 expression in bleomycin-induced pulmonary fibrosis: a negative feedback loop of TGF-beta signaling. Biochem Biophys Res Commun 2002;294:319-23.

17. Bonniaud P, Margetts PJ, Ask K, Flanders K, Gauldie J, Kolb M. TGF-beta and Smad3 signaling link inflammation to chronic fibrogenesis. J Immunol 2005;175:5390-5.

18. Tabata C, Kadokawa Y, Tabata R, Takahashi M, Okoshi K, Sakai Y, et al. All-trans-retinoic acid prevents radiation- or bleomycin-induced pulmonary fibrosis. Am J Respir Crit Care Med 2006;174:1352-60.

19. Yu Z, Xing Y. All-trans retinoic acid inhibited chondrogenesis of mouse embryonic palate mesenchymal cells by downregulation of TGF-beta/Smad signaling. Biochem Biophys 
Res Commun 2006;340:929-34.

20. Falk LA, De Benedetti F, Lohrey N, Birchenall-Roberts MC, Ellingsworth LW, Faltynek CR, et al. Induction of transforming growth factor-beta 1 (TGF-beta 1), receptor expression and TGF-beta 1 protein production in retinoic acid-treated HL60 cells: possible TGF-beta 1-mediated autocrine inhibition. Blood 1991;77:1248-55.

21. Cao Z, Flanders KC, Bertolette D, Lyakh LA, Wurthner JU, Parks WT, et al. Levels of phospho-Smad2/3 are sensors of the interplay between effects of TGF-beta and retinoic acid on monocytic and granulocytic differentiation of HL-60 cells. Blood 2003;101:498-507.

22. Taipale J, Matikainen S, Hurme M, Keski-Oja J. Induction of transforming growth factor beta 1 and its receptor expression during myeloid leukemia cell differentiation. Cell Growth Differ 1994;5:1309-19.

23. Furukawa F, Matsuzaki K, Mori S, Tahashi Y, Yoshida K, Sugano $\mathrm{Y}$, et al. p38 MAPK mediates fibrogenic signal through Smad3 phosphorylation in rat myofibroblasts. Hepatology 2003;38:879-89.

24. Harari S, Caminati A. IPF: new insight on pathogenesis and treatment. Allergy 2010;65:537-53.

25. Ryu JH, Moua T, Daniels CE, Hartman TE, Yi ES, Utz JP, et al. Idiopathic pulmonary fibrosis: evolving concepts. Mayo Clin
Proc 2014;89:1130-42.

26. Ross KR, Corey DA, Dunn JM, Kelley TJ. SMAD3 expression is regulated by mitogen-activated protein kinase kinase-1 in epithelial and smooth muscle cells. Cell Signal 2007;19:92331.

27. Gui T, Sun Y, Shimokado A, Muragaki Y. The roles of mitogenactivated protein kinase pathways in TGF-beta-induced epithelial-mesenchymal transition. J Signal Transduct 2012;2012:289243.

28. Engel ME, McDonnell MA, Law BK, Moses HL. Interdependent SMAD and JNK signaling in transforming growth factorbeta-mediated transcription. J Biol Chem 1999;274:37413-20.

29. Hartsough MT, Mulder KM. Transforming growth factor beta activation of $\mathrm{p} 44 \mathrm{mapk}$ in proliferating cultures of epithelial cells. J Biol Chem 1995;270:7117-24.

30. Thiery JP, Acloque H, Huang RY, Nieto MA. Epithelialmesenchymal transitions in development and disease. Cell 2009;139:871-90.

31. King TE Jr, Pardo A, Selman M. Idiopathic pulmonary fibrosis. Lancet 2011;378:1949-61.

32. Shi K, Jiang J, Ma T, Xie J, Duan L, Chen R, et al. Pathogenesis pathways of idiopathic pulmonary fibrosis in bleomycininduced lung injury model in mice. Respir Physiol Neurobiol 2014;190:113-7. 